\title{
MANAGING THE SUPPLY AND DEMAND UNCERTAINTY IN ASSEMBLY SYSTEMS
}

\author{
Hongze $\mathrm{Ma}^{1}$ and Kesheng Wang ${ }^{2}$ \\ ${ }^{1}$ Logistics, Turku School of Economics and Business Administration, Turku, Finland; E-mail: \\ Hongze.Ma@tukkk.fi. ${ }^{2}$ Norwegian University of Science and Technology, Trondheim, Norway
}

\begin{abstract}
To react to changing market rapidly, some companies outsource all components, and then assemble them into end product to fulfill customer demand. For such assembly systems, the marketing environment at both supply and demand sides is quite volatile. So, agility is one of the key factors for them to win the competition. In this paper, a simulation model is built for an assembly system, in which both supply and demand uncertainties are considered. Then, by this model, the effect of supply and demand uncertainty on the performance of the system is studied, and the approach on how to manage such uncertainties is provided. To achieve agility, managers of the assembly systems can utilize such results to adjust their assembly schedule to adapt to the different levels of supply and demand uncertainty.
\end{abstract}

Key words: Assembly system, inventory management, supply and demand uncertainty, simulation.

\section{INTRODUCTION}

In recent years, more and more companies, especially electronic companies, implement pure assembly system, i.e. outsource all the components, and assemble them into end products to fulfill customer demand. Such strategy possesses advantages of easy to start up and easy to achieve agility. But, at the same time, a company implementing pure assembly system also faces challenges of volatile component supply and customer demand. At the supply side, frequently updated product makes it difficult to organize the component procurement. At the demand side, shorter product life cycle makes the company difficult to forecast the customer demand. To meet these challenges, the operation managers in an

Please use the following format when citing this chapter:

Ma, Hongze, Wang, Kesheng, 2006, in International Federation for Information

Processing (IFIP), Volume 207, Knowledge Enterprise: Intelligent Strategies In Product Design, Manufacturing, and Management, eds. K. Wang, Kovacs G., Wozny M., Fang M., (Boston: Springer), pp. 322-327. 
assembly system need to position the safety stock levels wisely, and make the assembly schedule carefully. Especially, when the supply and demand variability changes, the managers need to adjust the safety stock and assembly schedule to adapt to the new situation.

In this paper, to study how to manage the supply and demand uncertainty, a simulation model for the assembly system is built, in which the supply and demand variability are considered. By this simulation model, the effect of supply and demand variability on the system performance is assessed, and the managerial implication on how to adjust safety stock to cope with different levels of variability is provided.

\section{LITERATURE REVIEW}

Inventory problems have been widely studied since the seminal work by Clark and Scarf. ${ }^{1}$ There are mainly two types of inventory control policies: continuous review policy ${ }^{4,6}$ and periodic review policy. ${ }^{2,3,4,5}$ Most of these models utilized mathematics to determine the optimal inventory control parameters. To model the complicated assembly systems, simulation techniques had been adopted. ${ }^{7,8,9}$ In most of the existing literatures, internal management for the system was taken as the main concern. But, the issues on how to react to the changing market environment were not well addressed. For example, when the variability of demand or supply changes, how will the company change its internal management to adapt to the new situation? In this paper, we will try to analyze the sensitivity of system performance to the changing variability in supply and demand, and then, based on this analysis, the managerial levers on how to adapt to the changed situation are provided.

\section{MODELING AND SIMULATION OF AN ASSEMBLY SYSTEM}

\subsection{The assembly system to be modeled}

In this paper, a two-echelon assembly system is considered. The BOM (Bill of Material) of the product to be assembled at the company is shown in Figure 1. The company purchases component $\mathrm{A}, \mathrm{C}$, and $\mathrm{D}$, and then assemble them into end product. Both supply and demand for this assembly system are uncertain. The customer demand at the end product is a random process with normal distribution. The uncertainty of component supply is expressed as random lead time. To deal with these uncertainties, the company needs to keep some safety stock. To manage this assembly system 
properly, the company needs to determine an optimal safety inventory level. Moreover, this safety stock level must be adjusted to adapt to the changing variability of supply and demand.

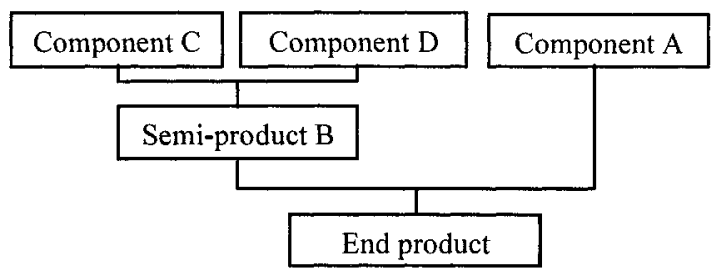

Figure 1. BOM of the product to be assembled

\subsection{The simulation model}

In this paper, we decided to use simulation technology to study this system. Vensim is selected to model and simulate the assembly system mentioned above. The entire model is divided into three parts: demand generating and fulfilling, product assembling, and component supply.

\subsubsection{Demand generating and fulfilling}

Demand is generated randomly with normal distribution. The variability level of demand is indicated by Mean Absolute Percentage Deviation (MAPD). After demand is generated, the end product inventory is checked. If there are enough products in the store, the demand is shipped; otherwise, it is backlogged. Concerning customer service, the performance of the system is indicated by fill rate. In the later part of this paper, the issues on how the system performance (i.e. fill rate) reacts to the different levels of demand variability (i.e. $M A P D$ of demand) will be addressed, and the corresponding managerial levers will be given.

\subsubsection{Product assembling}

The assembly process is organized according to the product's BOM. First, the inventory for components is checked, then, based on inventory status and assembly capacity, the production schedule is made. After a lead time, the end product is assembled. This lead time is random with normal distribution.

\subsubsection{Component supply}

When the at hand inventory (including the end product inventory and 
work-in-process) for a component is less than or equal to the reorder point, an order is placed at its supplier. The reorder point consists of two parts: lead time demand and safety stock. Safety stock is used to cover the uncertainty in both supply and demand. It has direct effect on customer service level, i.e. fill rate. In the later part of this paper, we will discuss: when the variability of demand and/or supply changes, how the safety stock will be adjusted to keep the same fill rate.

The order placed at the supplier will arrive at the assembly system after a lead time. This lead time is random with exponential distribution. Similar to customer demand, the level of variability for component supply is expressed by its MAPD of lead time.

\section{ANALYSIS OF SIMULATION RESULT}

\subsection{Managing the demand uncertainty}

The objective for this part is to find how to manage the assembly system when the demand variability changes. Generally, when safety stock increases, fill rate is improved. For a fixed safety stock, when demand variability increases, the fill rate declines, but their relationship is not linear. The larger the demand variability is, the more sensitive the fill rate is to the demand variability. When MAPD of demand is more than 0.5 , the backlogged demand increases remarkably as demand variability increases.

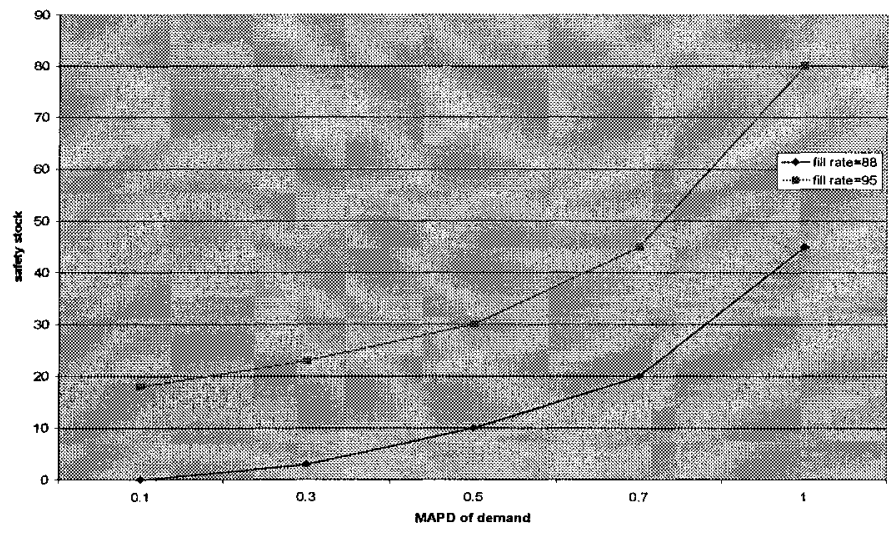

Figure 2. The needed safety stock to keep a given fill rate for different demand

In practice, when demand variability increases, we need to raise the safety stock to keep the given fill rate. The question is, how much to increase? 
Or in other words, for a given fill rate, which safety stock is needed for a demand variability? Figure 2 answers this question.

As shown in Figure 2, if we want to keep the fill rate more than $95 \%$, safety stock must be more than 18 when MAPD of demand is $0.1,30$ when MAPD is 0.5 , and 80 when MAPD of demand is around 1.0. By Figure 2, we may also get the following conclusion: when MAPD of demand is less than 0.5 , it is relatively easy to manage the demand uncertainty. We do not need to increase safety stock so much to compensate the increase in demand variability. When MAPD of demand is more than 1.0, it becomes very difficult to keep the fill rate more than $95 \%$.

\subsection{Managing the supply uncertainty}

In an assembly system, another uncertainty comes from supply side. Figure 3 shows how to adjust safety stock when supply MAPD changes. For example, if we want to keep fill rate more than $95 \%$, safety stock must be more than 15 when MAPD of supply is 0.1 , and 40 when MAPD of supply is 0.5 . It is more difficult to manage supply uncertainty when it is larger. For example, if we want to keep fill rate more than $95 \%$, safety stock must be more than 90 when MAPD of supply is 1.0. Moreover, for this level of supply uncertainty, fill rate does not increase significantly when we increase safety stock above 90 .

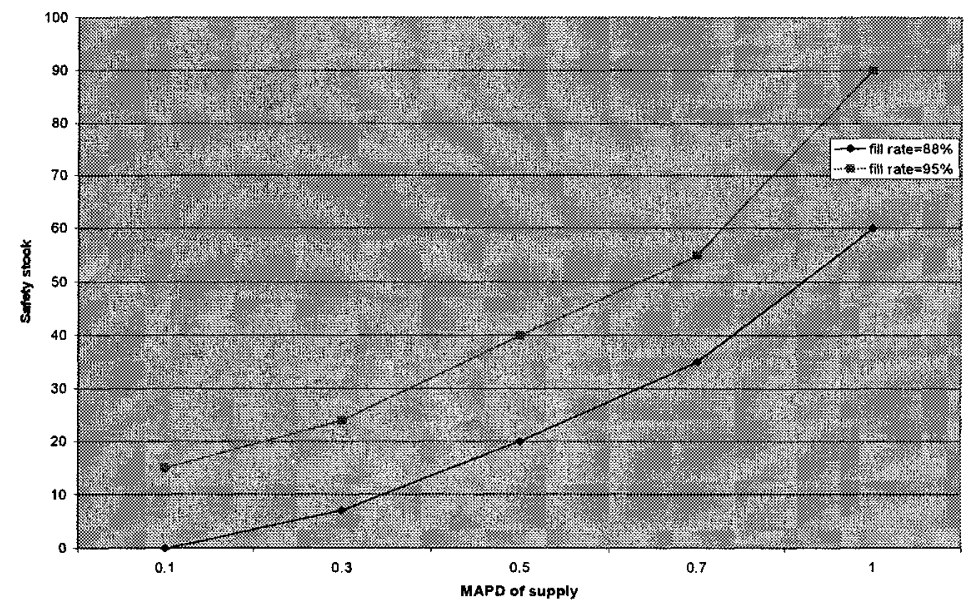

Figure 3 . The needed safety stock to keep a given fill rate for different supply variability

In this section, based on the simulation results, the issues on how to manage the supply and demand uncertainty are discussed, and the results are summarized in Figure 2 and Figure 3. To apply these results, first, a reasonable fill rate must be determined. Normally, if the cost in losing 
demand is high, a high fill rate needs to be kept; otherwise, fill rate can be relatively low to avoid high inventory. Chopra ${ }^{6}$ provided some formulae for determining optimal fill rate.

\section{CONCLUSION}

In managing an assembly system, one of the main difficulties is to deal with the uncertain environment. The uncertain delivery in component supply side and the variable order at the customer demand side are the main sources for this difficulty. In this paper, to find the way on how to manage the supply and demand uncertainty, a simulation model is built for an assembly system. In this model, the level of uncertainty for supply and demand is expressed as their Mean Absolute Percentage Deviation respectively, and the performance of the assembly system is measured by the fill rate. The reason for this arrangement is that, the uncertainty in supply and demand has direct influence on the fill rate for the customer demand. By this simulation model, the effect of supply and demand uncertainty on the performance of the system (i.e. fill rate) is assessed. Then, the approach on how to deal with the supply and demand uncertainty is provided. By these results, managers can adjust the safety stock level according to the observed supply and demand variability to keep a reasonable fill rate.

\section{REFERENCES}

1. Clark, A., Scarf, H., (1960), Optimal policies for multi-echelon inventory problem, Management Science 6, 475-490.

2. Diks, E.B., Kok, A.G., (1998), Optimal control of a divergent multi-echelon inventory system, European Journal of Operational Research.

3. Heijden, M., (1999), Inventory control in multi-echelon divergent systems with random lead times, Springer Verlag.

4. Graves, S.C., Willems, S.P., (2000), "Optimizing strategic safety stock placement in supply chains", Manufacturing Service Operation Management 2, 68-83.

5. Cachon, G.P., (2001), Exact evaluation of batch ordering inventory policies in two-echelon supply chains with periodic review, Operation Research, Vol. 49, No. 1.

6. Chopra, S., Meindl, P., (2004), Supply chain management: strategy, planning and operation, Prentice Hall, 250-340.

7. Bertolini, M., Rizzi, A., (2002), A simulation approach to manage finished goods inventory replenishment economically in a mixed push/pull environment, Logistics Information Management, Vol. 15, No. 4, pp. 281-293.

8. Bollapragada, R., Rao, U.S., Zhang, J., (2004), Managing inventory and supply performance in assembly systems with random supply capacity and demand, Management Science, Vol. 50, No., 12, pp. 1729-1743.

9. Decroix, G.A., Zipkin, P.H., (2005), Inventory management for an assembly system with product or component returns, Management Science, Vol. 51, Issues 8, pp. 1250-1266. 